\title{
The history of craniotomy for headache treatment
}

\author{
Rachid Assina, M.D., Christina E. Sarris, B.S., and Antonios Mammis, M.D. \\ Department of Neurological Surgery, New Jersey Medical School, Rutgers University, Newark, New Jersey
}

\begin{abstract}
Both the history of headache and the practice of craniotomy can be traced to antiquity. From ancient times through the present day, numerous civilizations and scholars have performed craniotomy in attempts to treat headache. Today, surgical intervention for headache management is becoming increasingly more common due to improved technology and greater understanding of headache. By tracing the evolution of the understanding of headache alongside the practice of craniotomy, investigators can better evaluate the mechanisms of headache and the therapeutic treatments used today.

(http://thejns.org/doi/abs/10.3171/2014.1.FOCUS13549)
\end{abstract}

KeY Words • headache • migraine • craniotomy • trepanation

$\mathrm{H}$ EADACHE has been described as long as human history has been recorded, having made its way into myth, magic, theology, and medicine. It has touched ordinary, privileged, and famous people, baffling the minds of the earliest physicians, who eagerly sought for means to explain its occurrence and methods for its treatment. Its history can be traced back at least 4000 years to Mesopotamian ritual texts. ${ }^{14}$ Headache was initially viewed as a spiritual entity rather than a symptom of various physical diseases. Scholars from numerous cultures and historical eras have contributed greatly to our modern-day understanding of the classification, pathophysiology, and treatment of headaches. Although the first descriptions of headaches, migraines, and neuralgias were recorded by the ancient Egyptians in the Ebers Papyrus, it was not until Hippocrates that headaches were classified as different types and attributed to real physical pathological states. ${ }^{20}$

Just as headache has been described for thousands of years, the history of trepanation (earlier) and then of craniotomy (later) can be traced back to prehistoric man. It is thought that the first cases of trepanation were most likely performed for religious or magical reasons, and later for treatment purposes to rid patients of conditions such as convulsive states, paresis, headaches, and, in particular, traumatic lesions. ${ }^{23}$ However, many of the reasons behind performing trepanation remain largely unknown and undocumented, particularly their relationship to the treatment of headache.

Surgical treatment of headache has evolved throughout history, and we will highlight in chronological order the practice of craniotomy for the treatment of headache in each historical era.

\section{From Prehistory Through the Babylonian Period}

The prehistoric era was marked by the lack of understanding of the human body and of the concept of disease and its origin. This period is also known in the neurosurgical field as the age of trepanation; that is, the removal of a piece of bone from the skull. Whereas the earliest documented descriptions of headache only date back 4000 years, its treatment may be traced back to the trepanation of Neolithic skulls 9000 years ago (Fig. 1). It is believed that trepanation was used to treat headaches by giving evil spirits a physical route to leave the ailing head. ${ }^{3}$ In the Mesopotamian period, headache was attributed to gods and evil spirits, in particular to Tiu, the evil spirit of headache. Treatment was based on appeasing or releasing the evil spirit with medicinal formulas or trepanation. ${ }^{5}$

Later, the Egyptians and Babylonians both introduced the concepts of diagnosis, prognosis, and medical examination. The Ebers Papyrus (c. 1550 BC), which is referred to as the oldest medical text, contains the first documented description of migraine headache, and proposes surgical treatment for the condition (Fig. 2). In addition to the many incantations that were invoked against migraine headaches and their accompanying symptoms such as nausea, trepanation was still practiced to release the demons from the suffering heads. ${ }^{6}$

\section{The Greco-Roman Period}

Ancient tales and folklore can be used as sources to unmask mysteries surrounding the development of early medical knowledge, and we find one of the first descrip- 


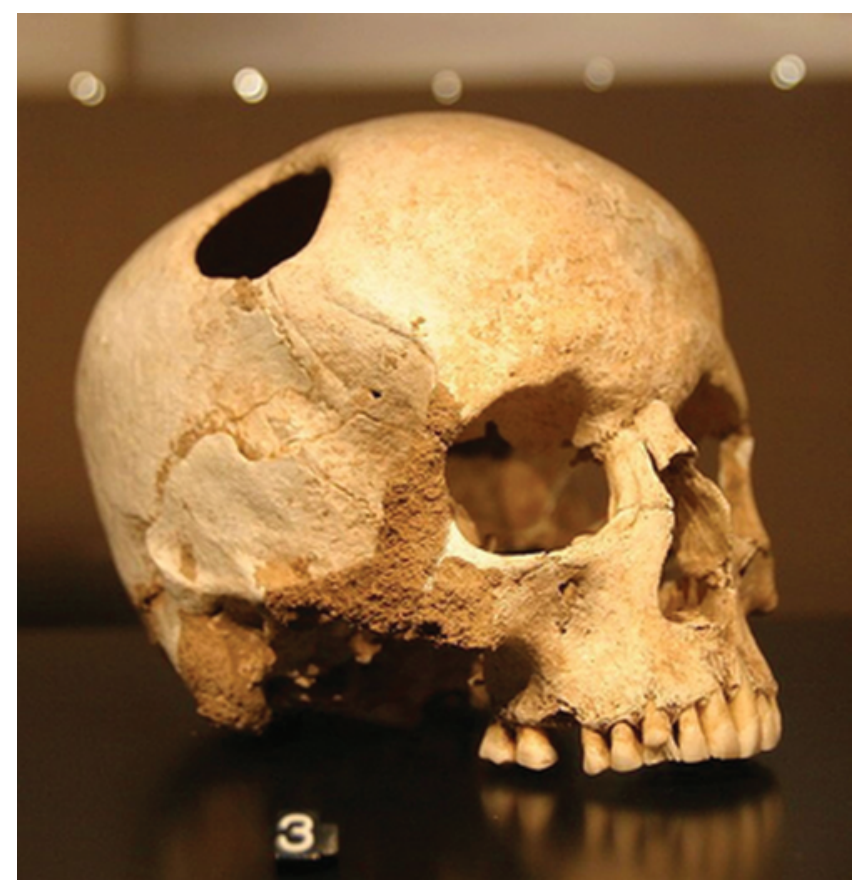

Fig. 1. Photograph of a trepanated skull of a female from the Neolithic Era. The trepanation defect shows new bone tissue growth, demonstrating that the patient survived the procedure. This skull is displayed in the Natural History Museum of Lausanne, Switzerland.

tions of trepanation for treatment of headache told through Greek mythology (Fig. 3). Around 700 вC, it was said that the ancient Greek god Hephaestus had once performed a craniotomy to relieve Zeus's excruciating headache caused by a mass growing inside his head (unbeknownst to Zeus, it was his daughter Athena). ${ }^{2}$ This classic story of Athena's birth, alleviating an unyielding headache by striking Zeus on the forehead with a double-headed axe to completely split the skull, ${ }^{10}$ emphasizes the rudimentary understanding of the development of headaches and the use of trepanation for their management ${ }^{2}$ (Fig. 4).

It was not until the time of Hippocrates (460-370 BC) (Fig. 5) that headache was first recognized as a symptom of a true disease rather than a spell from demons or gods. Although in his work On Injuries of the Head he describes and provides detailed instruction and clear warning of the dangers of trepanation, he does not mention its use in the treatment of headache. ${ }^{18}$ Later Hippocratic writers of Epidemics volumes IV and V circa 320 $\mathrm{BC}$ completed the list of reasons for trepanation, which included headache in suspected cases of pus under the skull. The late Hippocratic writers of the 3rd century $\mathrm{BC}$ outlined distinct reasons for trepanation, including to treat fractures and to remove dead bone; it is thought that headache was not specifically recorded as an indication for trepanation because it was implicit in the symptomatology of prior reasons. ${ }^{1}$

Later, as Koehler and van de Wiel ${ }^{12}$ recount, Aretaeus of Cappadocia (AD 30-90) in his Manual for the Treatment of Chronic Disease advocated reserving trepanation for persistent severe headaches.

Some physicians abrade or chisel the bone down to the diploe.... Others perforate the bone down to the meninges. These

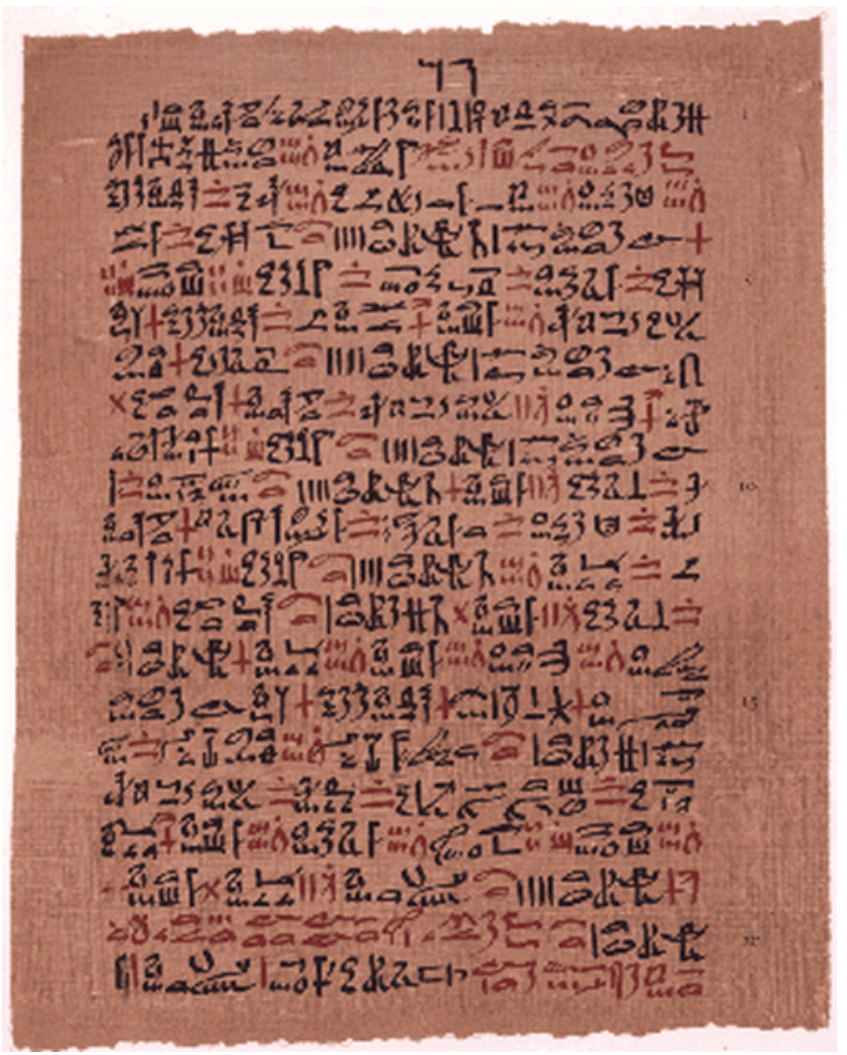

FIG. 2. Photograph of the Ebers Papyrus, dated circa $1550 \mathrm{BC}$ and known to be one of the oldest medical texts. It was found in Egypt in the 1870 s and contains prescriptions written in hieroglyphics for more than 700 remedies for a wide variety of afflictions, along with early descriptions of the circulatory system. The papyrus is kept at the library of the University of Leipzig in Germany. Image courtesy of the United States National Library of Medicine.

are hazardous treatments. You have to apply them when the headache persists after all that has been done...

\section{The Middle Ages}

Whereas trepanation was frequently performed in the prehistoric and classical Greco-Roman eras, medical treatments for headache were largely preferred during the Middle Ages by the Eastern, Arab, and Byzantine surgeons. Trepanation was performed only in extraordinary circumstances $^{23}$ (Fig. 6).

Guy de Chauliac (AD 1300-1368) was one of the few to advocate trepanation for headache; he proposed the procedure to Pope Clement VI who at the time was suffering an unremitting headache. ${ }^{15}$ During this period, however, treatments were largely focused on use of special solutions for compresses and ointments; surgical interventions were rare (Fig. 7).

\section{The Renaissance Period}

Because of the greater incidence in skull trauma during the Renaissance period due to the widespread use of firearms, trepanation again became a common procedure. ${ }^{23}$ However, as knowledge of the anatomy and 

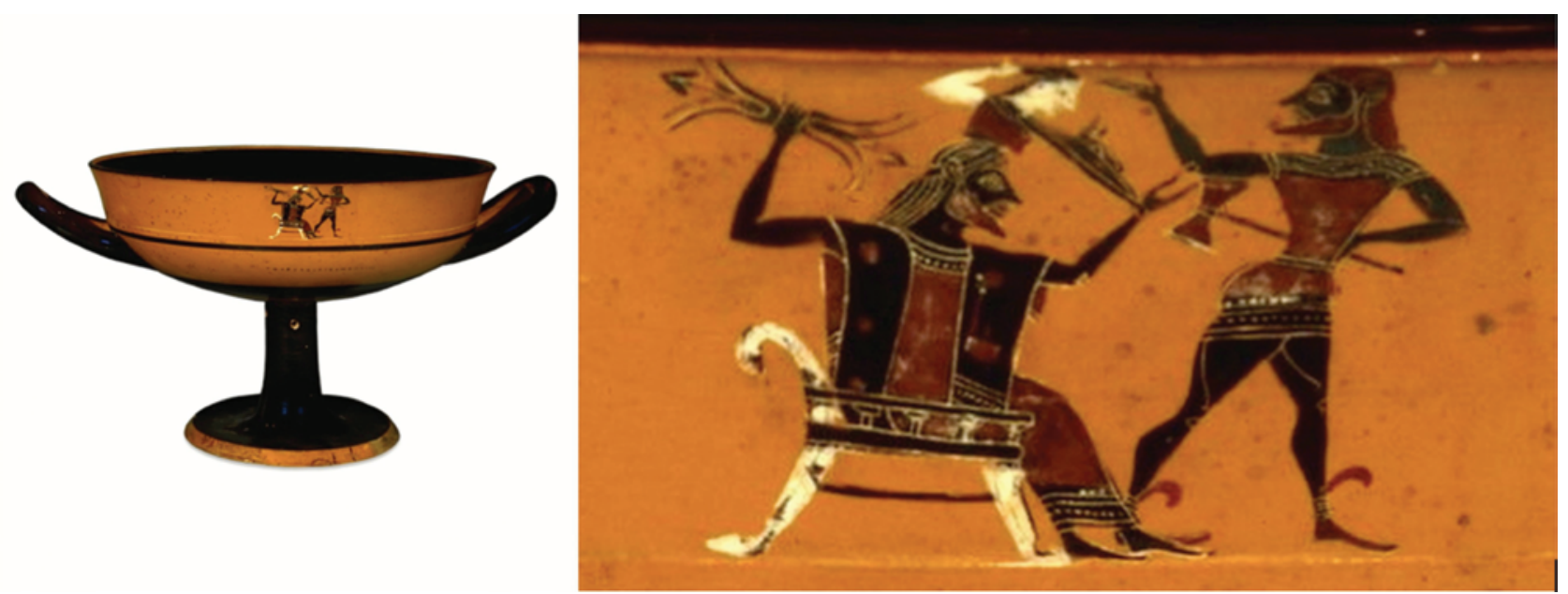

FIG. 3. Photograph of a Greek black-figured lip cup from circa $540 \mathrm{BC}$. Artwork illustrates the birth of the goddess Athena from her father Zeus's skull; the detail shows Hephaestus splitting Zeus's skull with a two-headed axe. Image courtesy of the Trustees of the British Museum.

physiology of the central nervous system rapidly expanded during this era, various other remedies for headaches were used; trepanation remained reserved for intractable cases. Prince Rupert of England underwent trepanation in 1667 for severe, unyielding headache, and reportedly recovered very well after pus was drained from under his skull; his headache was alleviated that day. ${ }^{1}$

Thomas Willis (AD 1621-1675), considered by many as the founder of clinical neuroscience, characterized numerous pathological states of the nervous system during his lifetime, including headache. In his chapter "Of the Head-ach" in The London Practice of Physick, ${ }^{24}$ with increased understanding of the many mechanisms that can result in headache, Willis offered explanations of and instructions for cure of many types of headaches. Although the majority of his proposed treatments involved medicinal therapies and cautery, he does mention trepanation for certain cases, with skepticism of its efficacy:
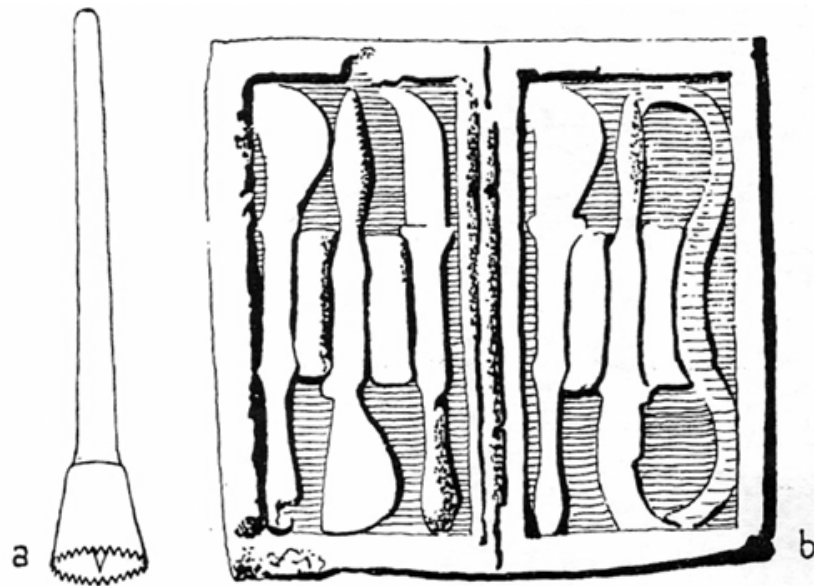

FIG. 4. Drawings of instruments used by ancient Greek surgeons. a: A trephine. b: A case of scalpels. In the time of Galen, the technique of trepanation became more sophisticated. Galen describes a variety of trephines, including those with guarded drills to help decrease injuries to the dura mater. ${ }^{18}$ Illustration from A Short History of Medicine. ${ }^{22}$
There remains yet another Chirurgical operation, extoll' $d$ by many for an obftinate Head-ach, but tried as yet by none (that I know) to wit, the opening of the Scull with a trepand Iron near the place of the pain: Our famous Harvey endeavour'd to perfwade a Lady of great quality to this, who was troubled with a terrible and inveterate Head-ach, promifing her a Cure thereby; but neither fhe nor any other has been content to admit of the adminiftration: Truly it does not appear to me what certainty we may expect from the Sculls being opened where it pains; if an Abfcefs lay hid there, this were the only way of Cure; but that is wont to caufe the fleepy, or mortal Convulsive affects, rather than to take away the Head-ach: if an inflamed Swelling, or Puftules, or an Eryfiela has feized the Diploii, I know not whether thofe tumours expofed to the naked Air will evaporate more eafily, or whether remedies applied to them, when bare, will do anything or not: And in cafe the pains arife by reafon of the Meninges being befet with tubercles, or a fchirrous, or callous Tumour, I judge the opening of the Scull will turn to little or no benefit.

Willis goes on to specify that opening the skull should only be performed if evident local disease is observed,${ }^{24}$ which can be considered a major progression in the evolution of the performance of trepanation for headache in subsequent time periods.

\section{The 18th Through 20th Centuries}

A great cultural movement of intellectuals who put emphasis on reason and scientific methods to advance knowledge and challenge the traditional and spiritual doctrines marked the 18th century. Clinical bedside medicine was reintroduced, with emphasis on diagnostic examination of the patient. Although surgeons during this period became more aggressive in the management of head pathology such as head trauma, ${ }^{4}$ the incidence of trepanation for headache treatment decreased, ${ }^{7,17,23}$ with an emphasis on bloodletting and fluid drainage from the body as the main treatment method of headaches. By 1800 , headache had been classified into categories of primary or secondary, as well as by cause: external, internal, idiopathic, febrile, inflammatory, hysterical, and so on. ${ }^{16}$ With greater understanding of the pathophysiology 


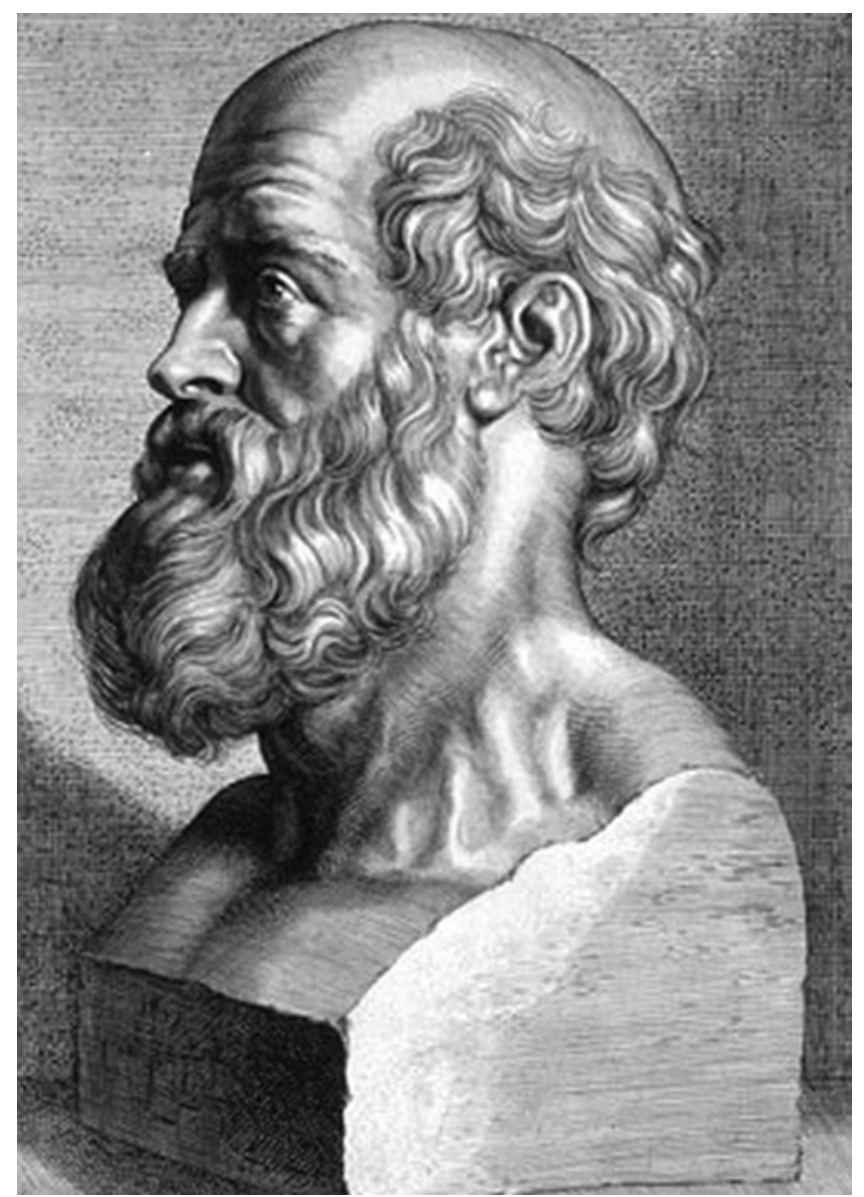

FIG. 5. Hippocrates. Engraving by Peter Paul Rubens in 1638. Hippocrates revolutionized medicine in the ancient world and contributed greatly to the development of neurological surgery. Image courtesy of the United States National Library of Medicine.

of such headaches, nonspecific treatment such as trepanation became less and less common in the Western world. Even so, for cases of intractable or inexplicable headache of the mid-19th century, surgical treatment of headache was still proposed. In his discussion of organic causes of headache, Dr. Allan McLane Hamilton ${ }^{8}$ mentions the intense headaches of cerebral tumor and their treatments.

Now that cerebral localization has been of such great aid to the surgeon and brain surgery has become a measure which is not necessarily a very dangerous one so far as operations that do not result in opening the dura mater are concerned, it seems as if relief might be afforded more often than it is; especially when evidence of cortical pressure are concerned; and when there is evident tension of the most tolerant of the meninges.

By the beginning of the 20th century, the migraine headache had been well established as its own entity, yet its causes and treatment remained most frustrating for physicians at the turn of the last century. Surgical management was attempted by Dr. Harvey Cushing, the father of modern neurosurgery during the early 1900 s, but many of his results were never published because many of his procedures proved to be unsuccessful. ${ }^{13}$

Cushing performed decompressive craniotomies localized over each patient's region of pain, and although some patients found a few months of relief, most migraines

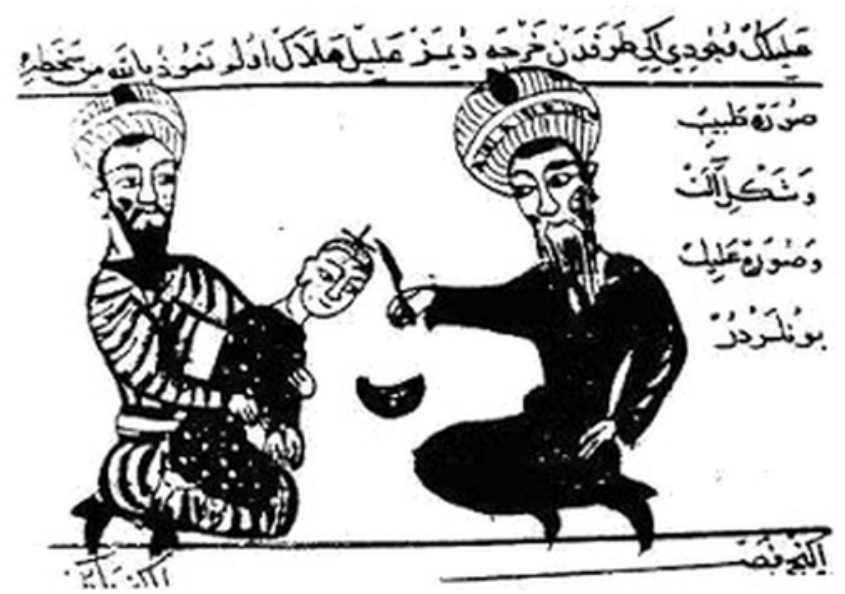

Fig. 6. Illustration of an Islamic doctor performing a scalp incision for a craniotomy. Islamic physicians contributed greatly to medicine after intellectual development began fading in Europe. In line with work from the Hippocratic and Galenic schools of thought, Islamic physicians similarly believed that headache stemmed from an unbalance of the four humors. Illustration from Cerrahiyyetu'l Haniyye, a 15th-century medicine book by Serafeddin Sabuncuoglu. ${ }^{21}$

returned (Fig. 8).$^{13}$ His efforts illustrate the limited understanding of migraine headache at the beginning of the 20th century, favoring the idea that increased intracranial pressure may be responsible for migraine headaches.

Colleagues of the same era held similar beliefs. During the same period, trepanation and craniotomy with third ventricle puncture were suggested in 1909 for the treatment of headache. ${ }^{11}$ In "An Address on the Treatment of Some of the Severer Forms of Headache," was suggested for a variety of headache types, including those from meningitis, cerebral tumor, and migraine.

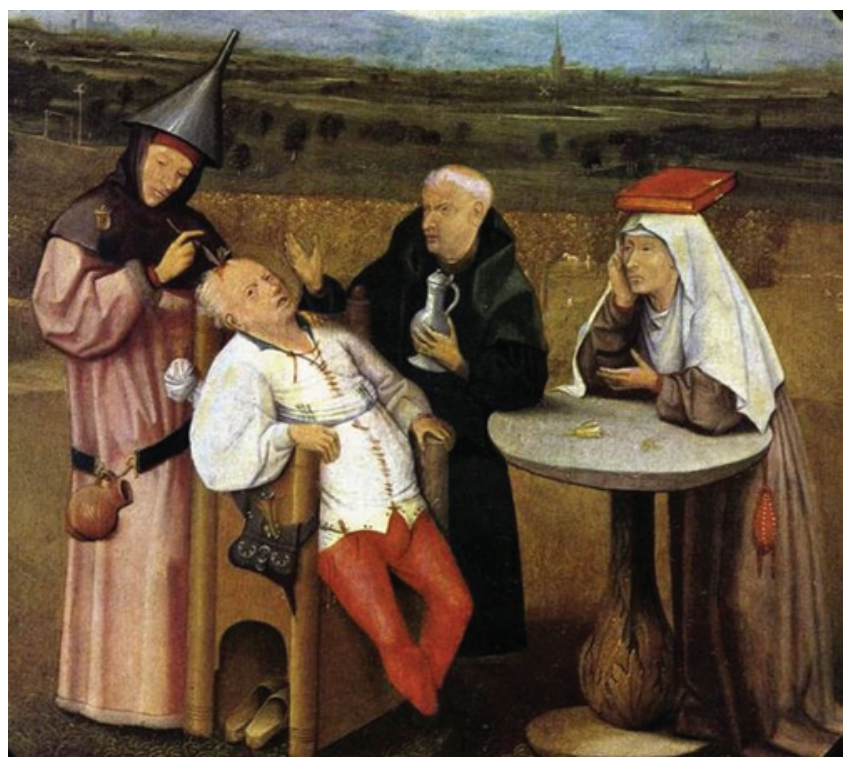

FIg. 7. Image of the painting The Extraction of the Stone of Madness, completed around 1494 by Hieronymus Bosch, demonstrating medieval trepanation. The work illustrates trepanation to remove a stone from the patient's head and presents one artist's view of the surgical procedure and medical knowledge during that time. The work is displayed in the Museo del Prado in Madrid. 

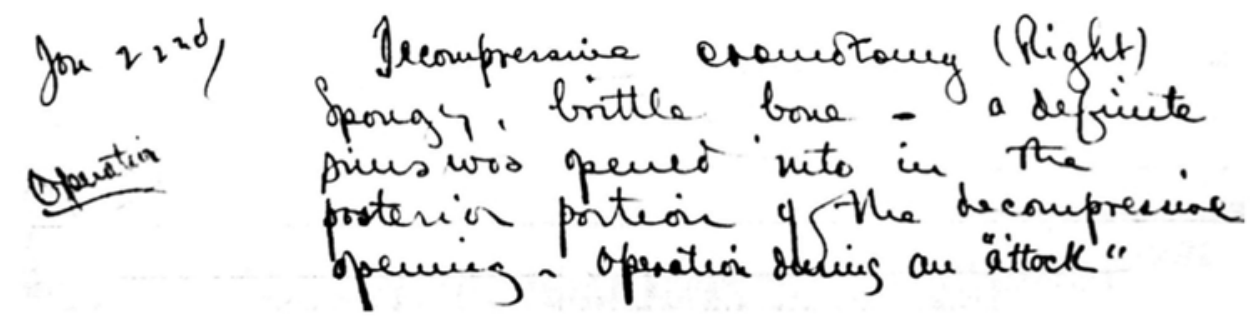

FIG. 8. Harvey Cushing's note describing one of his craniotomy procedures for headache treatment, which reads: "Decompressive craniotomy (Right) Spongy, brittle bone - a definite sinus was opened into in the posterior portion of the decompressive opening - Operation during an 'attack." Image courtesy of the Journal of Neurosurgery. Reprinted from Latimer K et al: $J$ Neurosurg 115:924-928, 2011.

To relieve the pain of migraine we must apply remedies which will lower the intracranial pressure, proceeding upon the same lines as we should for the relief of the headache in cerebral tumour or acute meningitis.... The operation of trephining has, I believe, never been done for the relief of migraine, though I have known it done several times for the cure of neurasthenic headache. I believe the operation would be justified in those severe cases of frequently recurrent migraine in which the unfortunate patient is prostrated for one or more days every week or so by the intense headache and sickness.

In another case of acute serous meningitis in a young girl with intense optic neuritis, all developing rapidly within three weeks, this same symptom of localized persistent pain and deep tenderness in the left posterior frontal region decided me to have the skull opened at that spot. As soon as the dura was opened the brain bulged through the trephine hole from the intense intracranial pressure, without any pulsation.... Her recovery was uneventful, though the discs now show slight signs of post-neuritic optic atrophy.

Headache management continued to trouble physicians throughout the 20th century. In the 1970s and 1980s, Morgenlander and Wilkins ${ }^{19}$ document 15 retromastoid craniectomies for the treatment of cluster headache, followed by sectioning of the main sensory root of the trigeminal nerve.

In civilizations around the world, craniotomy for treatment of headache survived at least until the 1990s. Trepanation for headache continued to occur among the Kisii of Uganda and Kenya, and it may still continue in Ethiopia, Tanzania, southern Sudan, and Somalia. Their procedures were performed by gouging an ellipse approximately 5 in long and 1 in wide into the crown of the head, and the scalp wound was allowed to close by scar formation. It has been suggested that these procedures are successful because a new source of pain from the surgical site competes for the same pain pathways used by the headache, and thus effectively blocks the headache pain from being perceived by the patient. ${ }^{1}$

\section{Conclusions}

The management of headache disorders continues to stimulate debate among physicians and scholars today in the 21 st century. From prehistoric times to perhaps modern-day culture in some civilizations, trepanation (earlier) and then craniotomy (later) have withstood the passage of time as treatments for numerous categories of headache. By tracing the evolution of headache knowledge alongside the practice of trepanation and craniotomy, we can better evaluate the mechanisms of headache and therapeutic treatments that are used today. As the field of neurosurgery progressively becomes more involved in the surgical management of a variety of headache types, it is important that we reflect on the surgical steps taken in the past to manage these diseases and use this knowledge to advance therapeutic strategies today.

\section{Disclosure}

The authors report no conflict of interest concerning the materials or methods used in this study or the findings specified in this paper.

Author contributions to the study and manuscript preparation include the following. Conception and design: Assina. Acquisition of data: Assina, Sarris. Drafting the article: Assina, Sarris. Critically revising the article: all authors. Reviewed submitted version of manuscript: all authors. Approved the final version of the manuscript on behalf of all authors: Mammis. Administrative/technical/material support: Mammis. Study supervision: Mammis.

\section{References}

1. Arnott R, Finger S, Smith CUM (eds): Trepanation: Discovery, History, Theory. Lisse, The Netherlands: Swets \& Zeitlinger, 2002

2. Brasiliense LB, Safavi-Abbasi S, Crawford NR, Spetzler RF, Theodore N: The legacy of Hephaestus: the first craniotomy. Neurosurgery 67:881-884, 2010

3. Campillo D: Neurosurgical pathology in prehistory. Acta Neurochir (Wien) 70:275-290, 1984

4. Ganz JC: Head injuries in the 18th century: the management of the damaged brain. Neurosurgery 73:167-176, 2013

5. Garrison FH, McHenry LC: History of Neurology, Revised and Enlarged. Springfield, IL: CC Thomas, 1969

6. Ghalioungui P: The Ebers Papyrus. Cairo: Academy of Scientific Research \& Technology, 1987

7. Gross C: A hole in the head. Neuroscientist 5:263-269, 1999

8. Hamilton AM: The Modern Treatment of Headaches. Detroit: GS Davis, 1888

9. Harris W: An Address on the Treatment of Some of the Severer Forms of Headache. Br Med J 2:297-298, 1908

10. Hesiod: Theogony: Works and Days, Shield, ed 2. Athanassakis AN, trans. Baltimore: Johns Hopkins University Press, 2004

11. Koehler PJ, Boes CJ: A history of non-drug treatment in headache, particularly migraine. Brain 133:2489-2500, 2010

12. Koehler PJ, van de Wiel TW: Aretaeus on migraine and headache. J Hist Neurosci 10:253-261, 2001

13. Latimer K, Pendleton C, Rosenberg J, Cohen-Gadol AA, Quiñones-Hinojosa A: Dr. Harvey Cushing's attempts to cure migraine based on theories of pathophysiology. Historical vignette. J Neurosurg 115:924-928, 2011 


\section{R. Assina, C. E. Sarris, and A. Mammis}

14. Magiorkinis E, Diamantis A, Mitsikostas DD, Androutsos G: Headaches in antiquity and during the early scientific era. $\mathbf{J}$ Neurol 256:1215-1220, 2009

15. Major RH: A History of Medicine. Springfield, IL: CC Thomas, 1954

16. McTavish JR: The headache in American medical practice in the 19th century: a historical overview. Headache 39:287-298, 1999

17. Mettler FA, Mettler CC: Historic development of knowledge relating to cranial trauma, in Browda J, Rabiner AM, Mettler FA (eds): Trauma of the Central Nervous System. Baltimore: Williams \& Wilkins, 1945

18. Missios S: Hippocrates, Galen, and the uses of trepanation in the ancient classical world. Neurosurg Focus 23(1):E11, 2007

19. Morgenlander JC, Wilkins RH: Surgical treatment of cluster headache. J Neurosurg 72:866-871, 1990

20. Rose FC: The history of migraine from Mesopotamian to Medieval times. Cephalalgia 15 (Suppl 15):1-3, 1995
21. Sabuncuoglu S: Cerrahiyyetu'l Haniyye. Istanbul: Istanbul University, 1465

22. Singer CJ, Underwood EA: A Short History of Medicine, ed 2. New York: Oxford University Press, 1962

23. Sperati G: Craniotomy through the ages. Acta Otorhinolaryngol Ital 27:151-156, 2007

24. Willis T: The London Practice of Physick, or the Whole Practical Part of Physick. London: T Bassett and W Crooke, 1685

Manuscript submitted December 5, 2013.

Accepted January 24, 2014.

Please include this information when citing this paper: DOI: 10.3171/2014.1.FOCUS13549.

Address correspondence to: Antonios Mammis, M.D., 90 Bergen St., Ste. 8100, Newark, NJ 07103. email: antonios.mammis@ rutgers.edu. 